\title{
Tissue engineered esophagus by copper-small intestinal submucosa graft for esophageal repair in a canine model
}

\author{
TAN Bo ${ }^{1,2,3 \dagger}$, WANG Min ${ }^{1 \dagger}$, CHEN Xi ${ }^{2}$, HOU JiangLong ${ }^{1,4}$, CHEN XiaoHe ${ }^{1}$, WANG Yue ${ }^{3}$, \\ LI-LING Jesse ${ }^{5}$ \& XIE HuiQi ${ }^{1,2^{*}}$ \\ ${ }^{1}$ Regenerative Medicine Research Center, West China Hospital, Sichuan University, Chengdu 610041, China; \\ ${ }^{2}$ Laboratory of Stem Cell and Tissue Engineering, State Key Laboratory of Biotherapy, West China Hospital, Sichuan University, \\ Chengdu 610041, China; \\ ${ }^{3}$ Department of Orthopedics, Sichuan Academy of Medical Sciences, Sichuan Provincial People's Hospital, Chengdu 610072, China; \\ ${ }^{4}$ Department of Thoracic and Cardiovascular Surgery, West China Hospital, Sichuan University, Chengdu 610041, China; \\ ${ }^{5}$ Institute of Genetic Medicine, School of Life Sciences, Sichuan University, Chengdu 610064, China
}

Received August 13, 2013; accepted October 1, 2013; published online January 16, 2014

\begin{abstract}
Acellular porcine small intestinal submucosa (SIS) has been used for esophagoplasty with success in a canine model. However, it did not lead to complete epithelialization. For better reconstruction, a cellular component is required. Moreover, promotion of angiogenesis with copper has been widely recognized by basic research as well as clinical studies. In this study, we have evaluated the feasibility and effectiveness of combined $\mathrm{Cu}$ and SIS (SIS-Cu patch) for the esophageal repair using a canine model. Eighteen male beagle dogs were subjected to surgical resection to produce cervical esophageal defects $(5 \mathrm{~cm}$ in length, $180^{\circ}$ in range). SIS with $\mathrm{Cu}$ (5 or $25 \mu \mathrm{mol} \mathrm{L}^{-1}$ copper) or without $\mathrm{Cu}$ was patched on the esophageal defects. Barium esophagram and histology exam were carried out to evaluate the effectiveness of the therapy. As shown, the SIS-Cu graft promoted re-epithelialization, re-vascularization and muscular regeneration. SIS-Cu patch is more effective than SIS alone for esophageal repair, and the SIS $+25 \mu \mathrm{mol} \mathrm{L}{ }^{-1} \mathrm{Cu}$ group demonstrated additional advantages over the $\mathrm{SIS}+5 \mu \mathrm{mol} \mathrm{L}-1 \mathrm{Cu}$.
\end{abstract}

esophagus, re-epithelialization, re-vascularization, muscle regeneration, copper, small intestinal submucosa

Citation: Tan B, Wang M, Chen X, Hou JL, Chen XH, Wang Y, Li L, Xie HQ. Tissue engineered esophagus by copper—small intestinal submucosa graft for esophageal repair in a canine model. Sci China Life Sci, 2014, 57: 248-255, doi: 10.1007/s11427-013-4603-0

Long gap atresia, cancer, Barrett's esophagus, and esophageal strictures and stenosis are pathologic statuses that necessitate esophageal replacement [1]. Many attempts have been made to design and develop artificial esophageal prostheses using appropriate biomaterials. At present, tissue engineered esophagus may be produced from natural, synthetic and composite biomaterials [2-7]. Biocompatibility of such materials, however, has been poor, and unfavorable complications including graft stricture and anastomotic

$\nmid$ Contributed equally to this work

*Corresponding author (email: xiehuiqi@scu.edu.cn) leakage are common. None of these esophageal prostheses has been clinically useful.

Porcine small intestinal submucosa (SIS) is an extracellular matrix (ECM)-based collagen material capable of inducing regeneration of various tissues [8]. Acellular SIS has been used for esophagoplasty with success in a canine model. Its tissue-specific construction or remodeling has resembled the natural organ in appearance as well as histology [9]. However, it could only result in partial epithelialization for esophagoplasty at 35 days after the surgery [9].

As prolonged epithelial regeneration may predispose to 
stenosis of the artificial esophageal stenosis, timely regeneration of epithelium is crucial for esophageal repair [10]. Although harvesting esophageal epithelial cells themselves may be ideal, pre-existing fibrotic, inflammatory or malignant changes can limit the use of esophageal tissues. Recently, cultured oral mucosal epithelial cell sheets have successfully reconstructed the ocular surfaces in both animal experiment and clinical practice [11-14]. Such cell sheets can also promote esophageal ulcer healing and prevent postoperative esophageal stenosis [15]. However, they could not promote tissue regeneration of entire or fullthickness esophagus due to lack of three-dimensional structures. A tissue-engineered esophageal patch using isolated autologous oral mucosal epithelial cells (OMECs) seeded on SIS has shown to be effective for esophageal repair following an artificial defect. Combined SIS and OMECs not only have resulted in faster recovery as demonstrated by barium esophagram and regain of body weight, but also promoted re-epithelialization and skeletal muscle regeneration [16]. However, insufficient numbers of autologous cells for esophagus engineering and clinical inconvenience still make alternative approaches highly demanding. Angiogenesis or vasculogenesis is an approach to overcome such problems to provide structural support for delivering oxygen and nutrients to the engineered esophageal grafts.

Promotion of angiogenesis using copper has been widely recognized by basic research and clinical study [17]. To overcome the shortcomings of SIS alone, cell sheets and autologous OMECs discussed above, this study was undertaken to evaluate the feasibility and effectiveness of combined $\mathrm{Cu}$ and SIS (SIS-Cu patch) for esophageal repair in a beagle dog model. The data obtained demonstrated that the graft of SIS-Cu can promote re-epithelialization, re-vascularization and muscular regeneration, and is more effective than SIS alone for esophageal repair.

\section{Materials and methods}

\subsection{Preparation of SIS loaded with $\mathrm{Cu}$}

SIS was prepared with standard procedures described previously $[18,19]$. Porcine small intestine was obtained and harvested from healthy home-raised pigs (around $100 \mathrm{~kg}$ at six months) within $4 \mathrm{~h}$ of sacrifice. It was cut in approximately $10 \mathrm{~cm}$ in length and washed with a saline solution. SIS was obtained by mechanical removal of tunica serosa and tunica muscularis, and cleaned by washing continuously with a saline solution. The submucous membrane was submerged in a solution containing methanol and chloroform $(1: 1, \mathrm{v} / \mathrm{v})$ in a fume cupboard for $12 \mathrm{~h}$ and rinsed with the deionized water to remove the organic solvents. Subsequently, the membrane was incubated in the $0.05 \%$ tryp$\sin / 0.05 \%$ ethylenediamine tetraacetic acid at $37^{\circ} \mathrm{C}$ for $12 \mathrm{~h}$ and rinsed with a saline solution continuously to remove the trypsin. Subsequently, the membrane was further treated with $0.5 \%$ sodium dodecylsulphate (SDS) in $0.9 \%$ sodium chloride by continuously shaking on a shaker for $4 \mathrm{~h}$. The detergent was then removed by thoroughly rinsing with a saline solution. Finally, the submucous membrane was soaked into $0.1 \%$ peroxyacetic acid and $20 \%$ ethanol for $30 \mathrm{~min}$ and rinsed with saline solution.

Five or $25 \mu \mathrm{mol} \mathrm{L}{ }^{-1}$ copper (II) sulfate solution was prepared, then per gram of SIS was soaked in $1 \mathrm{~L}$ of the solution overnight. It was frozen overnight at $-70^{\circ} \mathrm{C}$, lyophilized (CHRIST, GAMMA 2-16 LSC, Germany), sealed into hermetic packages, and then sterilized by gamma irradiation (25 KGY). The copper content of the SIS was determined by AAS according to standard procedures described previously.

\subsection{Experimental animals}

Eighteen male beagle dogs (one year old, weighing approximately $10 \mathrm{~kg}$ each) were purchased from Laboratory Animal Academy of Sichuan Medical Sciences Institute (license number, SCXK2004-15). The dogs were given standard dog food and free access to water. All animal experimental procedures were approved by Sichuan University Animal Care and Use Committee, following the Principles of Laboratory Animal Care formulated by the National Society for Medical Research.

\subsection{Surgical procedures}

Each dog had received an intramuscular injection of 0.04 $\mathrm{mg} \mathrm{kg}-1$ atropine and $15 \mathrm{mg} \mathrm{kg}^{-1}$ ketamine for premedication, followed by an intravenous injection of thiopental sodium (14-20 mg kg-1). Anesthesia was maintained by inhalation of isoflurane and oxygen through an endotracheal tube. A ventral cervical midline incision was made, and the esophagus was exposed by a blunt procedure. The removed esophageal section was around $5 \mathrm{~cm}$ in length and $2.5 \mathrm{~cm}$ in width $\left(180^{\circ}\right.$ in range). The defect site was patched with one layer SIS soaked in $5 \mu \mathrm{mol} \mathrm{Cu}$ (SIS+5Cu group, $n=6$ ), 25 $\mu$ mol $\mathrm{Cu}$ (SIS $+25 \mathrm{Cu}$ group, $n=6)$, or SIS only $(n=6)$. The grafts were sutured to the adjacent normal esophagus with 5-0 Prolene in a continuous, simple pattern. The incision was closed anatomically with 5-0 absorbable (poliglycolid acid) suture in an interrupted pattern. The specimens of excised normal esophagus were placed in $10 \%$ neutral buffered formalin for later use as controls for immunohistochemical evaluation. Each dog was given intravenous fluids $\left(60 \mathrm{~mL} \mathrm{~kg}{ }^{-1}\right.$ ) containing antibiotics (cefazolin, $500 \mathrm{mg}$, intravenously) for $3 \mathrm{~d}$ after the operation. The dogs were not given any food by mouth for $3 \mathrm{~d}$ after the surgery, and then started to eat soft $\mathrm{dog}$ food for $7 \mathrm{~d}$, followed by a return to normal diet. 


\subsection{Esophageal function assessment and histological examination}

Body weight of all dogs was closely monitored. Eight weeks after the operation, they were subjected to barium esophagram and sacrificed. Esophageal tissue specimens were obtained. All specimens were fixed in $10 \%$ neutrally buffered formalin for H\&E and Masson's trichrome staining.

\subsection{Assessment of inflammation}

Inflammatory cells in the H\&E-stained tissue sections were counted under a microscope. For each section, inflammatory cells were counted from 12 randomly selected microscopic fields.

\subsection{Immunohistochemistry}

Sections of the paraffin-embedded preparations described above were also used for immunohistochemical analysis. Using indirect immunoperoxidase method, immunohisto chemical staining was carried out with rabbit antihuman endothelial cell CD31 monoclonal antibody (1:250, Epitmics, USA). Briefly, paraffin-embedded sections were deparaffinized, rehydrated, and blocked with $10 \%$ normal serum. Subsequently, the sections were treated with respective primary monoclonal antibody and secondary antibody (goat anti rabbit IgG, KPL, Gaithersburg, USA) according to the manufacturer's recommendations.

\subsection{Measurement of vascular density}

The number of microvessels $(<20 \mu \mathrm{m}$ in diameter) in the patch area was counted under a light microscope (400x magnification). Five high-power fields in the patch area were chosen at random, and microvessels were counted in each field. The number of microvessels in each field was averaged, and vascular density was expressed as the number of microvessels per unit area $\left(0.2 \mathrm{~mm}^{2}\right)$ [20].

\subsection{Statistical analysis}

Data were presented as mean \pm standard deviation (SD). Statistical analysis was performed using a one-way ANOVA, and the difference between groups was analyzed with SNK-q test (SPSS for window, version 15.0). $P<0.05$ was considered statistically significant.

\section{Results}

\subsection{Therapeutic effect of SIS and SIS with $\mathrm{Cu}$}

All dogs had survived the surgery, with cervical wounds remaining intact with no evidence of infection or fistula formation. None of the dogs had developed dysphagia, vomiting or salivation. All animals showed a weight loss at 7 days after the operation, but had regained their body weight by 34 days (SIS $+5 \mathrm{Cu}$ group), 27 days ( $\mathrm{SIS}+25 \mathrm{Cu}$ group), and 51 days (SIS group), respectively (Figure 1).

Barium esophagram showed no evidence of leakage, stricture or diverticulum formation eight weeks after the operation. However, the esophageal lumen surface at the site of the patch graft in the $\mathrm{SIS}+5 \mathrm{Cu}$ and $\mathrm{SIS}+25 \mathrm{Cu}$ groups appeared to be smoother than that of the SIS group (Figure 2A-C).

The patch graft sites were visible in all dogs sacrificed eight weeks after the operation. The lumen surface of the segmental esophageal sample was exposed. A partial fibrous mesh protrusion was observed in the SIS group (Figure $3 \mathrm{~A})$. By contrast, the lumen surface of the graft was smooth in the SIS-Cu groups (Figure $3 \mathrm{~B}$ and $\mathrm{C}$ ). The lumen surface of the SIS $+25 \mathrm{Cu}$ group (Figure 3C) appeared to be smoother than that of the other two groups.

\subsection{Histological findings}

Eight weeks after the operation, partial epithelial coverage of the grafts, consisting of a substantial number of inflammatory cells, was identified in the SIS group (Figure 4, A1-A3). However, a grade 3 epithelial lining, judged by a previously published criteria [8], was observed in all examined dogs from the SIS+5Cu group (Figure 4, B1-B3) and $\mathrm{SIS}+25 \mathrm{Cu}$ group (Figure 4, C1-C3). Mild inflammation was detected in $\mathrm{SIS}+25 \mathrm{Cu}$ group. The number of inflammatory cells in the SIS group was greater than that of the $\mathrm{SIS}+5 \mathrm{Cu}$ group or $\mathrm{SIS}+25 \mathrm{Cu}$ group $(* *, P<0.01)$. $\mathrm{SIS}+5 \mathrm{Cu}$ group had more inflammatory cells compared with SIS+ $25 \mathrm{Cu}$ group $(*, P<0.05)$ (Figure $4 \mathrm{D})$.

For the SIS group, no regeneration of isolated muscle

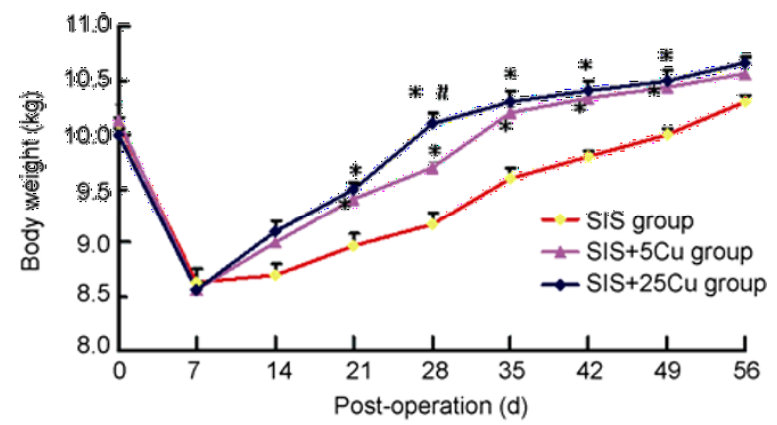

Figure 1 Changes in body weight (mean \pm SD) from 0 to 56 days among the SIS, SIS $+5 \mathrm{Cu}$ and $\mathrm{SIS}+25 \mathrm{Cu}$ groups. Weight loss has occurred rapidly 7 days following the operation in all the dogs. The animals had regained their body weight respectively by 51 (SIS group), 34 (SIS $+5 \mathrm{Cu}$ group) and 27 days (SIS $+25 \mathrm{Cu}$ group) after the operation. *, $P<0.01$ vs. SIS group; \#, $P<0.05$ vs. SIS $+5 \mathrm{Cu}$ group. 

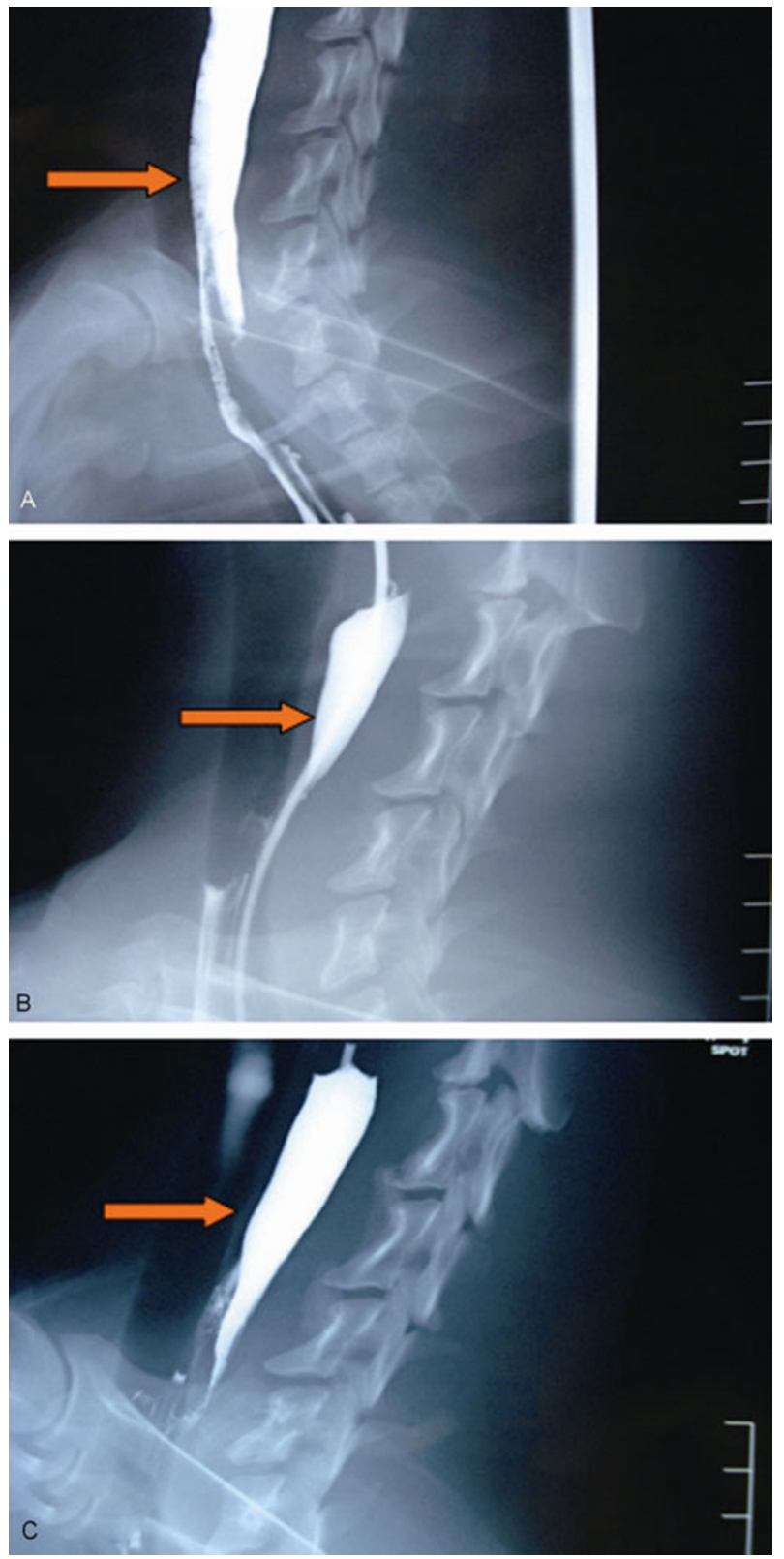

Figure 2 Contrast esophagram eight weeks after operation. There was no evidence for leakage, stricture or diverticulum formation in each group. The esophageal lumen surface in both $\mathrm{SIS}+5 \mathrm{Cu}$ (B) and $\mathrm{SIS}+25 \mathrm{Cu}$ groups (C) appeared to be smoother than the SIS group (A). Arrow indicates the site of the patch graft.

cells was observed, except that a few short bundles of skeletal muscle from adjacent area have extended into the graft (Figure 5A and B). By contrast, for both SIS $+5 \mathrm{Cu}$ (Figure $5 \mathrm{C}$ and $\mathrm{D}$ ) and $\mathrm{SIS}+25 \mathrm{Cu}$ groups (Figure $5 \mathrm{E}$ and $\mathrm{F}$ ), the submucosal tissues were well organized, and many bundles of the skeletal muscles from the adjacent area have extended into the graft. There were also isolated or clusters of muscle cells surrounded by collagenous connective tissue matrix in the SIS $+5 \mathrm{Cu}$ (Figure $5 \mathrm{C}$ and $\mathrm{D}$ ) and $\mathrm{SIS}+25 \mathrm{Cu}$ groups (Figure 5E and F).
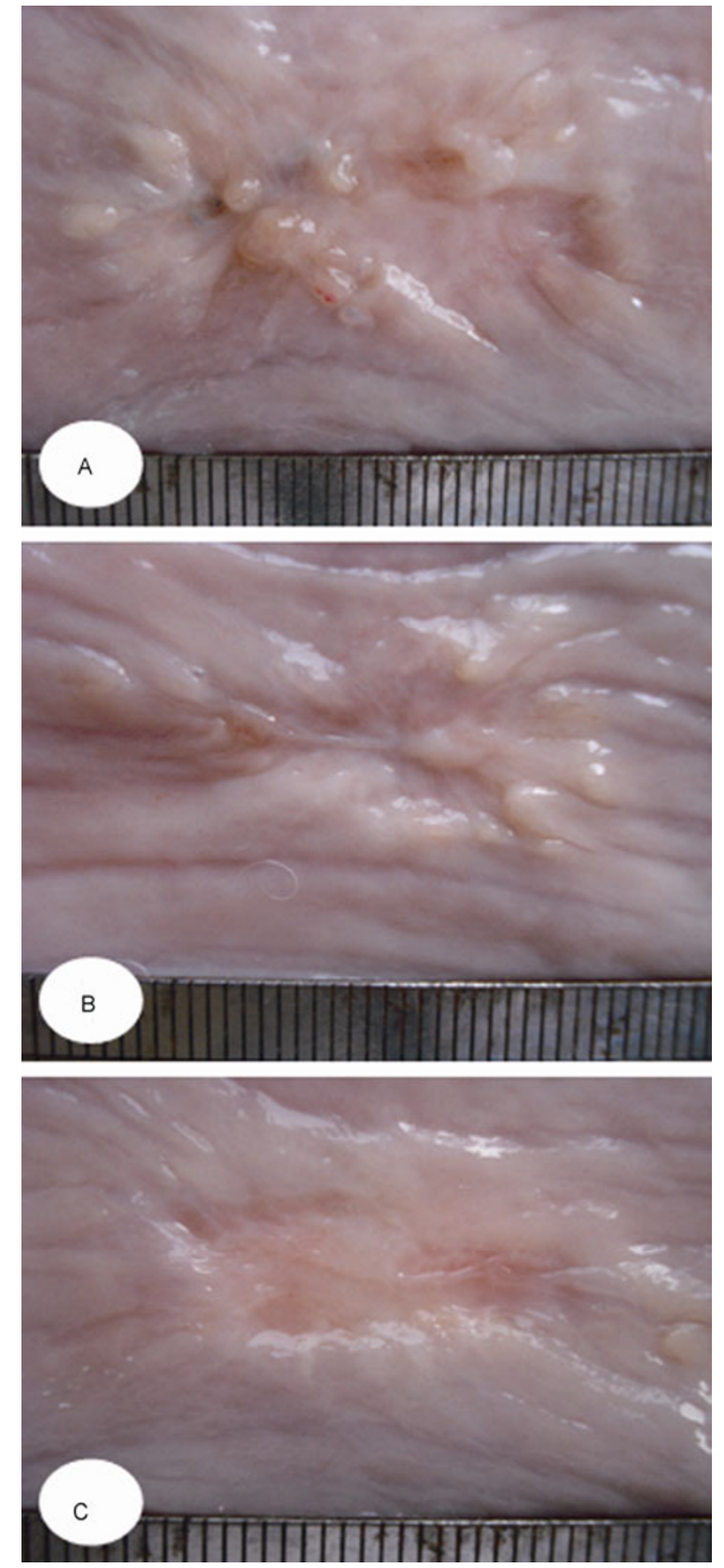

Figure 3 Gross anatomy of the removed esophageal segment eight weeks following the operation. A, The partial fibrous mesh protrusion was observed in the SIS group. B, The lumen surface of the graft appeared to be smooth in the SIS $+5 \mathrm{Cu}$ group. C, The lumen surface of the graft in the $\mathrm{SIS}+25 \mathrm{Cu}$ group was distinctively smoother compared with the other two groups.

\subsection{Increased vascular density in patch areas treated with SIS-Cu patches}

The numbers of $\mathrm{CD} 31^{+}$capillaries in the patch area of the $\mathrm{SIS}-\mathrm{Cu}$ treated groups were significantly greater compared with the SIS group (Figure 6A). Both the SIS+5Cu (Figure $6 \mathrm{~B}$ ) and SIS+25Cu (Figure 6C) groups exhibited a significant increase in the number of vessels in the patch area. The microvessel density in the $\mathrm{SIS}+25 \mathrm{Cu}$ group was much 


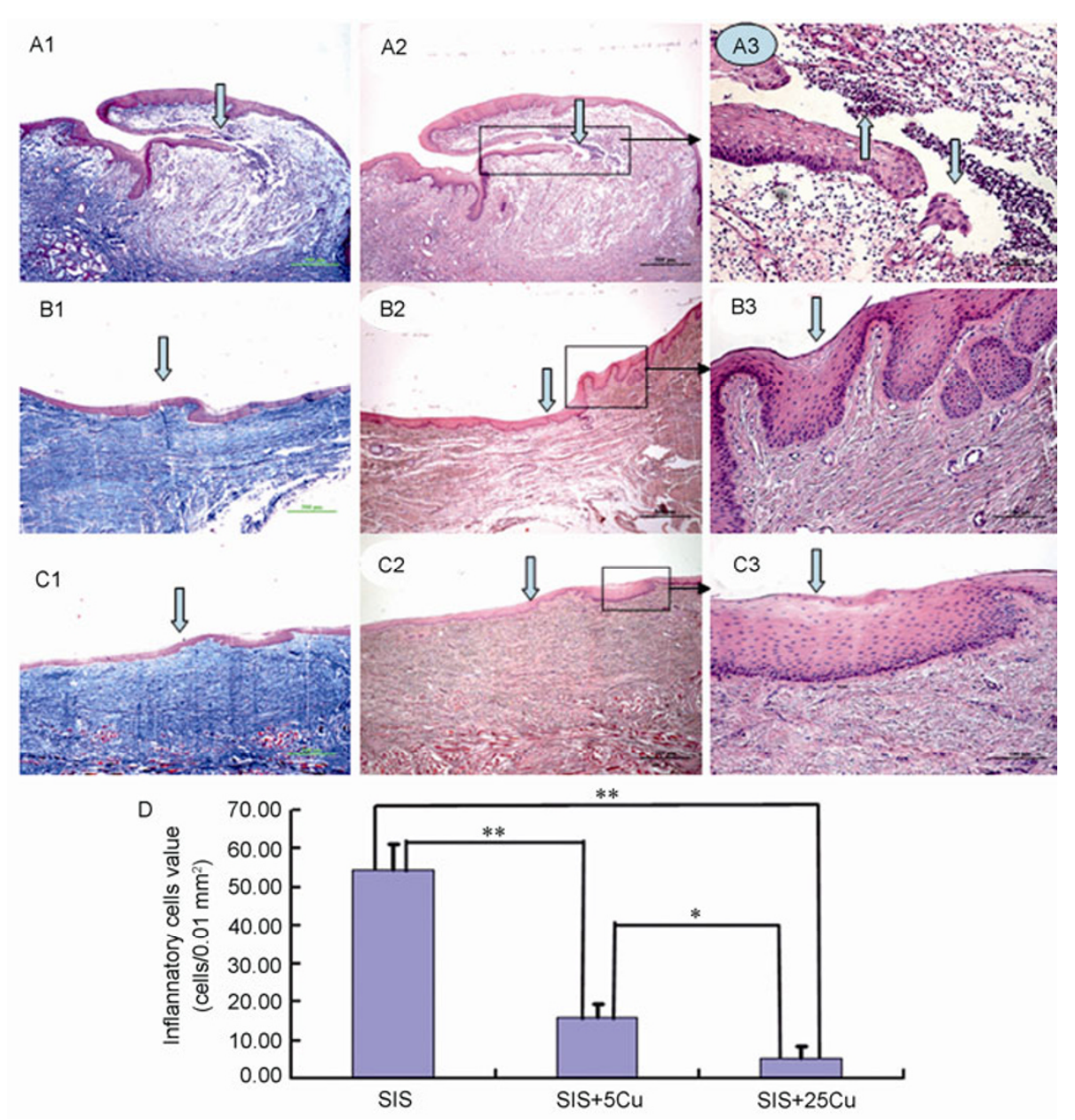

Figure 4 Epithelialization and postoperative inflammation of the three groups eight weeks after operation. H\&E and Masson's trichrome staining showed only the partial immature squamous epithelium coverage (down arrowhead $\downarrow$ ) in the central graft in the SIS group. There was considerably more accumulation of the inflammatory cells (up arrowhead $\uparrow$ ) (A1-A3). H\&E and Masson's trichrome staining showed the intact squamous epithelial coverage (down arrowhead $\downarrow$ ) and almost no inflammation in the SIS+5Cu (B1-B3) or SIS+25Cu groups (C1-C3), and with underlying well organized fibroblastic cells in the SIS+25Cu group (C2 and C3). The number of inflammatory cells in the SIS group was larger than that of the SIS+5Cu group or SIS+25Cu group (**, $P<0.01)$, and that of the $\mathrm{SIS}+5 \mathrm{Cu}$ group was larger than that of the $\mathrm{SIS}+25 \mathrm{Cu}$ group $(*, P<0.05)$ (D).

greater than the $\mathrm{SIS}+5 \mathrm{Cu}$ group. The numbers of microvessels have measured 4.12 $\pm 1.03,6.22 \pm 0.58$ and $7.88 \pm 0.57$ in the SIS, SIS $+5 \mathrm{Cu}$ and $\mathrm{SIS}+25 \mathrm{Cu}$ groups, respectively (Figure 6D).

\section{Discussion}

Replacement of esophagus for the treatment of congenital and acquired diseases has remained a great challenge [21-25]. During the last decade, several organic and synthetic biomaterials have been tried to replace part or full circumference of the esophagus. These, however, have been associated with a high rate of complications such as anastomotic leakage [26].

Esophagus is a muscular tube that transverses three anatomical planes (neck, thorax, and abdomen) and serves as a conduit to transport food and fluids from mouth to the stomach [27]. To engineer long-term implants with no leak or stenosis and with epithelialization over the entire lumen of the implanted scaffold will be of paramount importance [28]. In particular, stratified squamous epithelial cells predominantly compose the lumen epithelium and serve as a barrier or protective layer in response to the mechanical stresses produced by the food bolus during peristaltic contractions [29]. Therefore, epithelialization on the surface of artificial scaffold has been considered the most crucial aspect for providing natural esophageal functions in tissue-engineered substitutes. It is necessary to evaluate the formation of epithelial layers under in vivo conditions.

We have developed a tissue engineered esophageal patch using SIS combined with autologous OMECs to promote re-epithelialization and muscular regeneration, which has proven to be more effective than SIS alone for esophageal repair. Moreover, $\mathrm{Cu}$ promotion of angiogenesis has been a topic for both basic and clinical research, which may over- 

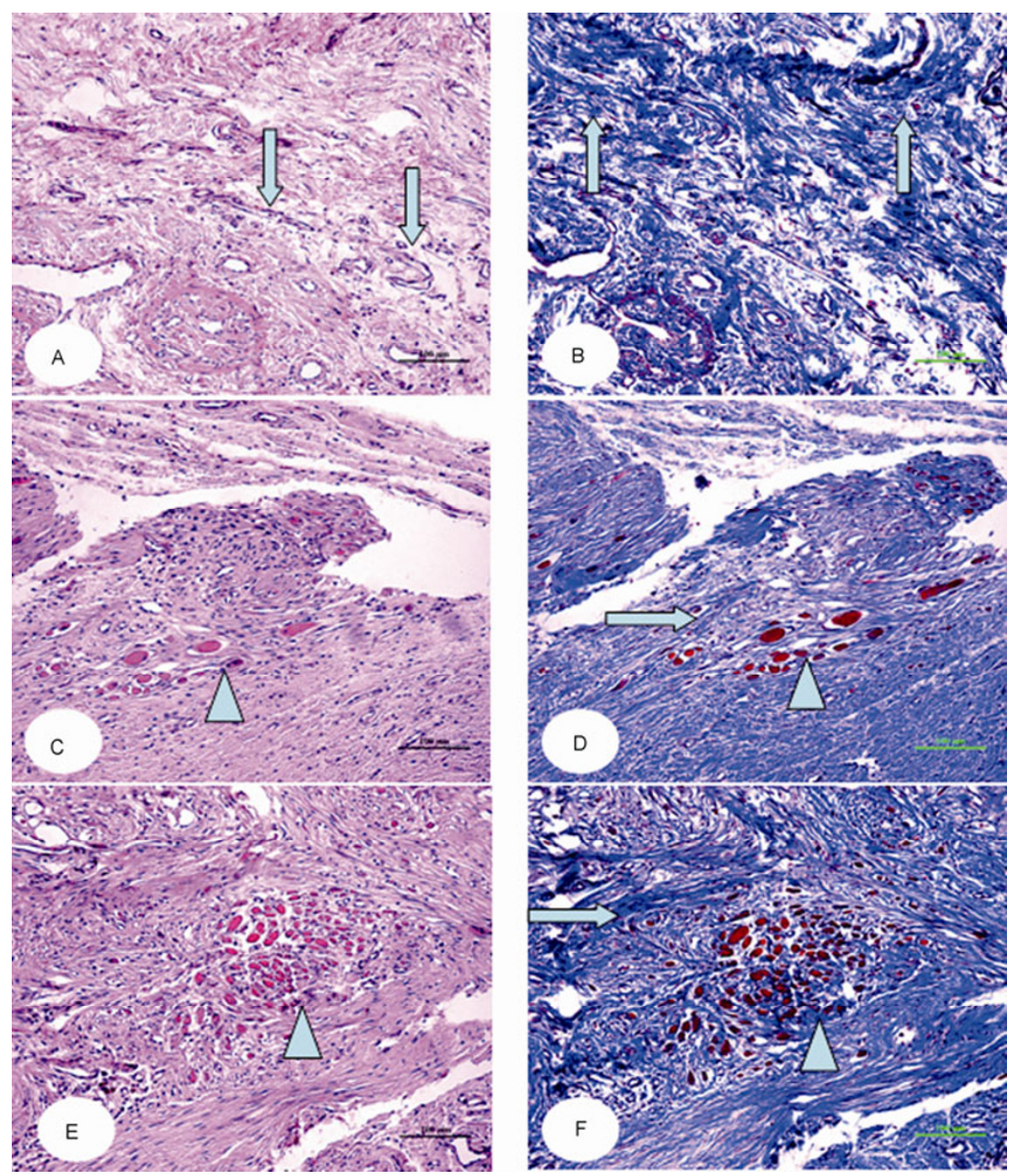

Figure 5 Histological findings eight weeks after the operation. A, H\&E staining showed formation of many new blood vessels (down arrowhead $\downarrow$ ) but no regeneration of muscle cells among the collagen fibers in the SIS group. B, Organized undulated collagen fibers (up arrowhead $\uparrow$ ) were observed by Masson's trichrome staining in the SIS group. H\&E staining showed many clusters of muscle cells (triangular arrowhead $\Delta$ ) in both SIS+5Cu (C) and $\mathrm{SIS}+25 \mathrm{Cu}$ group (E). Masson's trichrome staining showed the clusters of muscle cells (triangular arrowhead $\Delta$ ) surrounded by the collagenous connective tissue matrix (horizontal arrowhead $\rightarrow$ ) in the $\mathrm{SIS}+5 \mathrm{Cu}(\mathrm{D})$ and $\mathrm{SIS}+25 \mathrm{Cu}$ group (F).

come the shortcomings of SIS alone, cell sheets and autologous OMECs. There was a complete epithelialization with almost no inflammation in the SIS-Cu groups eight weeks post operation. By contrast, there was only a partial epithelialization along with evident inflammation in the SIS group. The promotion of re-epithelialization could greatly enhance the healing process. Importantly, it can also prevent stenosis of the artificial esophagus [30,31]. On the other hand, the mild inflammation found in the SIS-Cu group may delay the regain of body weight for the dogs.

Both SIS and SIS-Cu have adequately supported the healing of esophageal defect. None of the dogs had developed vomiting or salivation. Barium esophagram also has found no evidence of leakage, stricture or diverticulum in either SIS-Cu group or SIS group. However, the regain of body weight after the surgery was faster in the SIS-Cu groups.

Lack of sufficient vascularization may induce necrosis in bioengineered tissue thicker than $100-200 \mathrm{~mm}$. In celldense tissue fabrication, it is critical to reconstruct reliable vascular networks for supplying oxygen and essential nutrients with sufficiency while removing metabolic wastes. New technologies for improving cell-dense tissues accompanied with well-organized vascular networks are strongly desired. Importantly, our data have demonstrated that the microvessel densities in both $\mathrm{SIS}+5 \mathrm{Cu}$ and $\mathrm{SIS}+25 \mathrm{Cu}$ groups are greater than that in the SIS group (SIS $+25 \mathrm{Cu}$ group in particular).

For investigating whether tissue-engineered esophagus has functions such as transport of food bolus, efforts need to be made in the engineering of oriented smooth muscle myoarchitecture to mimic the circular and longitudinal config- 

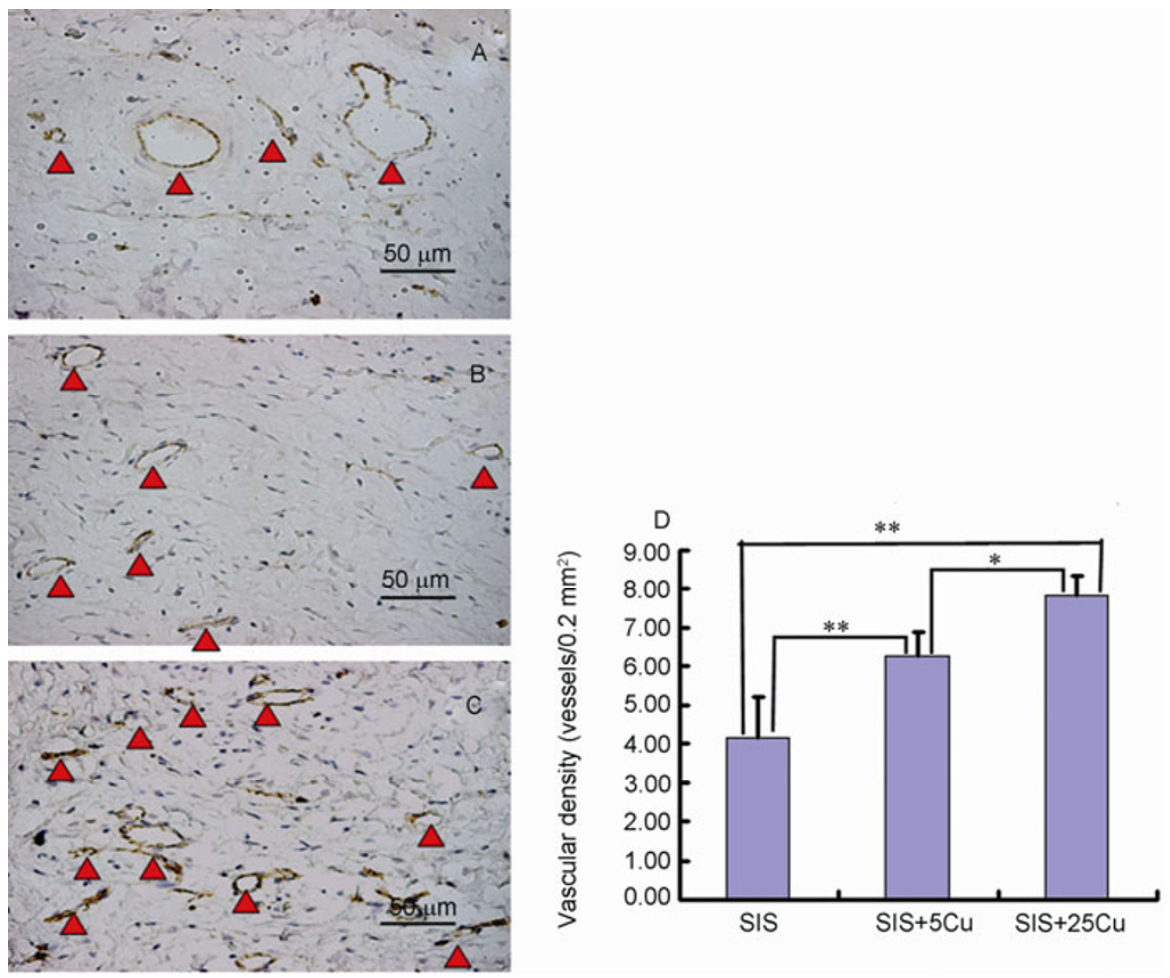

Figure 6 The numbers of $\mathrm{CD} 31^{+}$capillaries (triangular arrowhead $\Delta$ ) in the patch area of the $\mathrm{SIS}+5 \mathrm{Cu}(\mathrm{B})$ and $\mathrm{SIS}+25 \mathrm{Cu}(\mathrm{C})$ group were greater than that of the SIS group (A) $(* *, P<0.01)$. The SIS $+25 \mathrm{Cu}$ group had more CD31 ${ }^{+}$capillaries compared with the $\mathrm{SIS}+5 \mathrm{Cu}$ group $(*, P<0.05)(\mathrm{D})$.

urations of the natural organ [31]. Treatment with SIS-Cu has resulted in evident extension of muscle cell bundles and occurrence of island muscle cells in the connective tissue eight weeks after the operation. Although prolonged observation may also reveal the appearance of isolated muscle cells in the connective tissue of the SIS group, faster muscle regeneration is more in favor of esophageal repair.

The data obtained in the present study showed satisfactory repair of the esophagus with SIS combined with $\mathrm{Cu}$. Although both SIS and SIS-Cu groups have shown effective repair of an artificial esophageal defect simulating clinical operation of tumor removal, the SIS-Cu demonstrated more advantages over the SIS alone. Combined SIS-Cu not only resulted in a faster recovery, but also promoted re-epithelialization and re-vascularization. The effect is more predominant in the $\mathrm{SIS}+25 \mathrm{Cu}$ group.

In summary, our study has demonstrated the feasibility and effectiveness of SIS-Cu for esophageal repair in a canine model. Our results suggested that this may provide an alternative treatment for esophageal defects, which has more advantages over current approach. For future studies, attempts should be made to introduce an SIS tubular construct $\left(360^{\circ}\right.$ in range) for replacement of cervical esophagus using the same model.

The authors thank Li XiuQun and Li QunYing (Regenerative Medicine Research Center, West China Hospital, Sichuan University) for their technical support. We also thank Prof. Y. James Kang (Regenerative Medicine
Research Center, West China Hospital, Sichuan University) for his comments and advice in the elaboration of the manuscript. This work was jointly supported by the National Natural Science Foundation of China (31271058 and 81100327) and the National High Technology Research and Development Program of China (2012AA020503).

1 Saxena AK, Baumgart H, Komann C, Ainoedhofer H, Soltysiak P, Kofler K, Höllwarth ME. Esophagus tissue engineering: in situ generation of rudimentary tubular vascularized esophageal conduit using the ovine model. J Pediatric Surg, 2010, 45: 859-864

2 González Sáez LA, Arnal Monreal F, Pita Fernández S, Machuca Santa Cruz J. Experimental study using PTFE (Goretex) patches for replacement of the oesophageal wall. Eur Surg Res, 2003, 35: 372-376

3 Urita Y, Komuro H, Chen G, Shinya M, Kaneko S, Kaneko M, Ushida T. Regeneration of the esophagus using gastric acellular matrix: an experimental study in a rat model. Pediatr Surg Int, 2007, 23: 21-26

4 Zhu Y, Leong MF, Ong WF, Chan-Park MB, Chian KS. Esophageal epithelium regeneration on fibronectin grafted poly (L-lactide-cocaprolactone) (PLLC) nanofiber scaffold. Biomaterials, 2007, 28: 861-868

5 Zani A, Pierro A, Elvassore N, Coppi PD. Tissue engineering: an option for esophageal replacement? Semin Pediatr Surg, 2009, 18: $57-62$

6 Musahl V, Abramowitch SD, Gilbert TW, Tsuda E, Wang JH, Badylak SF, Woo SL. The use of porcine small intestinal submucosa to enhance the healing of the medial collateral ligament $-\mathrm{a}$ functional tissue engineering study in rabbits. J Orthop Res, 2004, 22: 214-220

7 Tan B, Xie HQ. Tissue engineering applications in esophagus of reparative and reconstructive surgery. Acta Biophys Sin, 2011, 6: 475-482

8 Lopes MF, Cabrita A, Ilharco J, Pessa P, Patrício J. Grafts of porcine intestinal submucosa for repair of cervical and abdominal esophageal 
defects in the rat. J Invest Surg, 2006, 19: 105-111

9 Badylak S, Meurling S, Chen M, Spievack A, Simmons-Byrd A. Resorbable bioscaffold for esophageal repair in a dog model. J Pediatric Surg, 2000, 35: 1097-1103

10 Yamamoto Y, Nakamura T, Shimizu Y, Matsumoto K, Takimoto Y, Liu Y, Ueda H, Sekine T, Tamura N. Intrathoracic esophageal replacement with a collagen sponge-silicone double layer tube: evaluation of omental-pedicle wrapping and prolonged placement of an inner stent. ASAIO J, 2000, 46: 734-739

11 Nakamura T, Endo K, Cooper LJ, Fullwood NJ, Tanifuji N, Tsuzuki M, Koizumi N, Inatomi T, Sano Y, Kinoshita S. The successful culture and autologous transplantation of rabbit oral mucosal epithelial cells on amniotic membrane. Invest Ophthalmol Vis Sci, 2003, 44: 106-116

12 1Nakamura T, Inatomi T, Sotozono C, Amemiya T, Kanamura N, Kinoshita S. Transplantation of cultivated autologous oral mucosal epithelial cells in patients with severe ocular surface disorders. Brit J Ophthalmol, 2004, 88: 1280-1284

13 Inatomi $\mathrm{T}$, Nakamura $\mathrm{T}$, Kojyo $\mathrm{M}$, Koizumi $\mathrm{N}$, Sotozono $\mathrm{C}$, Kinoshita S. Ocular surface reconstruction with combination of cultivated autologous oral mucosal epithelial transplantation and penetrating keratoplasty. Am J Ophthalmol, 2006, 142: 757-764

14 Nishida K, Yamato M, Hayashida Y, Watanabe K, Yamamoto K, Adachi E, Nagai S, Kikuchi A, Maeda N, Watanabe H, Okano T, Tano Y. Corneal reconstruction with tissue-engineered cell sheets composed of autologous oral mucosal epithelium. N Engl J Med, 2004, 351: 1187-1196

15 Ohki T, Yamato M, Murakami D, Takagi R, Yang J, Namiki H, Okano T, Takasaki K. Treatment of oesophageal ulcerations using endoscopic transplantation of tissue-engineered autologous oral mucosal epithelial cell sheets in a canine model. Gut, 2006, 55: 1704-1710

16 Wei RQ, Tan B, Tan MY, Luo JC, Deng L, Chen XH, Li XQ, Zuo X, Zhi W, Yang P, Xie HQ, Yang ZM. Grafts of porcine small intestinal submucosa with cultured autologous oral mucosal epithelial cells for esophageal repair in a canine model. Exp Biol Med, 2009, 234: 453-461

17 Xie HQ, Kang YJ. Role of copper in angiogenesis and its medicinal implications. Curr Med Chem, 2009, 16: 1304-1314

18 Badylak SF, Lantz GC, Coffey A, Geddes LA. Small intestinal submucosa as a large diameter vascular graft in the dog. J Surg Res, 1989, 47: 74-80
19 Luo JC, Chen W, Chen XH, Qin TW, Huang YC, Xie HQ, Li XQ, Qian ZY, Yang ZM. A multi-step method for preparation of porcine small intestinal submucosa (SIS). Biomaterials, 2011, 32: 706-713

20 Silva GV, Litovsky S, Assad JA, Sousa AL, Martin BJ, Vela D, Coulter SC, Lin J, Ober J, Vaughn WK, Branco RV, Oliveira EM, He R, Geng YJ, Willerson JT, Perin EC. Mesenchymal stem cells differentiate into an endothelial phenotype, enhance vascular density, and improve heart function in a canine chronic ischemia model. Circulation, 2005, 111: 150-156

21 Lambert R, Hainaut P. The multidisciplinary management of gastrointestinal cancer. Epidemiology of oesophagogastric cancer. Best Pract Res, 2007, 21: 921-945

22 Patrick Jr CW, Mikos AG, McIntire LV. Frontiers in Tissue Engineering. New York: Pergamon, 1998. 598-609

23 Leonard GD, McCaffrey JA, Maher M. Optimal therapy for oesophageal cancer. Cancer Treat Rev, 2003, 29: 275-282

24 Saxena AK, Kofler K, Ainödhofer H, Höllwarth ME. Tissue engineering: hybrid approach with esophageal epithelium and unidirectional smooth muscle tissue component generation in vitro. J Gastrointest Surg, 2009, 13: 1037-1043

25 Gallo A, Cha C. Updates on esophageal and gastric cancers. World J Gastroenterol, 2006, 12: 3237-3242

26 Baleur YL, Gaujoux S, Bruneval P. Self-expanding removable plastic stents for the protection of surgical anastomoses after esophageal replacement in a porcine model. Gastrointest Endosc, 2010, 72: 790-795

27 Saxena AK, Ainoedhofer H, Höllwarth ME. Esophagus tissue engineering: in vitro generation of esophageal epithelial cell sheets and viability on scaffold. J Pediatric Surg, 2009, 44: 896-901

28 Lindberg K, Badylak SF. Porcine small intestinal submucosa (SIS): a bioscaffold supporting in vitro primary human epidermal cell differentiation and synthesis of basement membrane proteins. Burns, 2001, 27: 254-266

29 Zhu YB, Ong WF, Chan W, Li Y, Liu Y. Construct of asymmetrical scaffold and primary cells for tissue engineered esophagus. Mater Sci Eng C, 2010, 30: 400-406

30 Sakurai T, Miyazaki S, Miyata G, Satomi S, Hori Y. Autologous buccal keratinocyte implantation for the prevention of stenosis after EMR of the esophagus. Gastrointest Endosc, 2007, 66: 167-173

31 Tan B, Wei RQ, Tan MY, Luo JC, Deng L, Chen XH, Hou JL, Li XQ, Yang ZM, Xie HQ. Engineered esophagus by mesenchymal stem cell seeding for esophageal repair in a canine mode. J Surg Res, 2013, 182: $40-48$

Open Access This article is distributed under the terms of the Creative Commons Attribution License which permits any use, distribution, and reproduction in any medium, provided the original author(s) and source are credited. 